\title{
Importance of Trace Minerals in the Ration of Breeding Bull - A Review
}

\author{
Ravi Prakash Pal*, Veena Mani, Shahid Hassan Mir, \\ Ram Kumar Singh and Rachana Sharma
}

NDRI, Karnal, Haryana, India

*Corresponding author

\begin{tabular}{|l|l}
\hline \multicolumn{1}{c}{ A B S T R A C T } \\
\cline { 2 - 3 } $\begin{array}{l}\text { Keywords } \\
\text { Trace minerals, Ration, } \\
\text { and breeding bull. }\end{array}$ & $\begin{array}{l}\text { Proper feeding management of the breeding bulls becomes more important for } \\
\text { production of good quality semen. Ration of breeding bull need to supply essential } \\
\text { nutrients to sustain life and maximize production of semen. Essential nutrients are } \\
\text { classified as energy, protein, water, vitamins and minerals. Minerals are classified } \\
\text { as Major and trace mineral. Trace mineral play an important role in male } \\
\text { reproduction, as an imbalance in their amounts may lead to defective } \\
\text { Article Info }\end{array}$ \\
\hline $\begin{array}{l}\text { Accepted: } \\
\text { 04 September 2017 } \\
\text { Available Online: } \\
\text { 10 November 2017 }\end{array}$ & $\begin{array}{l}\text { Supplementation of mineral has the ability to increase male reproductive } \\
\text { performance that is why mineral in the ration of breeding bull cannot be ignored. } \\
\text { This review will provide information to understanding the important role of trace } \\
\text { minerals in breeding bull for good semen production. }\end{array}$ \\
\hline \hline
\end{tabular}

\section{Introduction}

Reproductive performance of animals is the reflection of many factors, individually and in combination, springing from different aspects viz; genetics, nutrition, management and environment (Kumar, 2003). These different areas are equally significant; however, nutrition is most important aspect as it can be easily manipulated and has profound effect on animal reproductive performance. After energy and protein, minerals are the major nutrients and should be required in order to optimize reproduction in breeding bull. Deficiency of minerals may leads to certain structural, physiological or immunological disorder affecting growth, production and reproductive health of breeding bull. Minerals are important in reproductive processes due to their direct role in maintenance, metabolism and growth. Trace minerals nutrition is critical, since even minute fluctuation in their levels will have significant impact on reproductive health and performance of animals (Hedaoo et al., 2008).

Trace minerals are required in small amounts (<100 mg/kg DM) (McDowell, 1992; NRC, 1996) and are present in very minute quantities in animals $(<50 \mathrm{mg} / \mathrm{kg})$. Requirements of minerals for reproduction and immunity are generally greater than maintenance requirement of bull which might require supplementation of that mineral. Supplementation of minerals in ration of breeding bulls requires good knowledge of 
bioavailability, sources of mineral, requirement of animal and mineral interactions with other nutrients. Trace mineral such as Se (Selenium), Zn (Zinc), $\mathrm{Cu}$ (copper), Mn (manganese), Co (Cobalt), Fe (Iron) and I (Iodine) are important in male fertility because of their importance in the functioning of different enzymes and protein. Trace minerals have a great impact on animal's reproductive physiology and its deficiency or excess causes various problems leading to lowered reproductive efficiency and resultant pecuniary loss to the dairy industry.

Adequate micro minerals supplementation is required for bull fertility because most of the roughages, greens, concentrates, unconventional feed and even most of commercial feeds available to Indian market are deficient in trace mineral elements, as in most parts of the India soils are deficient in trace element such as $\mathrm{Cu}, \mathrm{Zn}, \mathrm{Fe}$ and $\mathrm{Mn}$.

Correcting an imbalance in mineral levels can solve this problem by improving reproductive performance and health of bull with little additional cost. Terrain and agroclimatic area of India is quite diverse in respect to mineral status, so one therapeutic treatment may not be suitable for other regions. Hence there is a need to map the mineral status in different soils, fodders and animals, so accordingly an area specific mineral may be formed and then supplemented to bulls.

Trace minerals are present in the animal almost entirely as organic complexes or chelates and not as free inorganic ions. Thus, it has been suggested that dietary organic trace minerals could be more efficiently utilized in body. Studies indicate that organic forms of trace minerals can improve reproductive performance of animal more than their inorganic counterparts, particularly during times of stress.

\section{Zinc}

Zn plays an important role in the immune system and certain reproductive hormones formation. Synthesis of testosterone is dependent on adequate dietary $\mathrm{Zn}$. It is a structural part of protein that involved in synthesis and secretion of testosterone. It seems to have regulatory role in the level of dihydrotestosterone by modulating the 5areductase activity, as zinc has been reported to affect the testicular function by activating adenylcyclase system, which stimulates the testosterone synthesis. It is also needed for the normal functioning of the hypothalamuspituitary-gonadal axis which plays an important role in production and secretion of FSH, LH and prolactin and these in turn, regulate testosterone production (Bedwal and Bahuguna, 1994). A deficiency of $\mathrm{Zn}$ in males reduces testicular development, sperm production, poor semen quality and libido. Minerals such as $\mathrm{Cu}, \mathrm{Cd}, \mathrm{Ca}$ and $\mathrm{Fe}$ act as antagonist for $\mathrm{Zn}$ and reduce $\mathrm{Zn}$ absorption and interfere with its metabolism. Requirement of $\mathrm{Zn}$ in diet of cattle is $40 \mathrm{ppm}$ (NRC, 2001) and toxic Zn dietary concentration is $500 \mathrm{ppm}$ for all classes of beef cattle, including bulls. The $\mathrm{Zn}$ levels in seminal plasma are 10-15 folds higher than those in blood plasma of the bull (Dhami et al., 2001; Roy, 2006). Testicular atrophy is the direct consequence of $\mathrm{Zn}$ deficiency. A positive correlation exists between testicular development and semen quality so $\mathrm{Zn}$ deficiency leads to poor semen quality. $\mathrm{ZnSO}_{4}$ and $\mathrm{Zn}$ propionate in the diet of crossbred cattle bulls have improved semen quality in terms of quantitative and qualitative characteristics of semen (Kumar et al., 2006). Organic form of $\mathrm{Zn}$ ( $\mathrm{Zn}$ propionate) showed a better response in improving sperm per ejaculate, mass motility and semen fertility test like bovine cervical mucus penetration test (Kumar et al., 2006). It controls the motility of sperms by influencing 
development of flagellar system of spermatozoa tail. Zn localizes in the sperm middle piece in association with lipoprotein fraction and it is involved in catabolism of lipid, which is the principle source of energy required for movement of spermatozoa. High concentration of $\mathrm{Zn}$ in the spermatozoa is essential for viability and fertility of bull. $\mathrm{Zn}$ has a role in reducing circulating anti-sperm antibodies which prevents asthenozoospermia, which is associated with high level of anti-sperm antibodies (Omu et al., 1988). Zn plays an important role in the preservation of the nuclear chromatin which undergoes decondensation at the stage of male genome transfer during fusion and thus plays a crucial role in fertilization. It helps to increase the functional life of ejaculated sperm. Production of semen demand extensive cell division, which requires a large amount of $\mathrm{Zn}$ as it is involved extensively in nucleic acid and protein metabolism. Hence, $\mathrm{Zn}$ supplementation is inevitable to bulls producing higher semen volume, sperm concentration, percentage of live sperm and motility. It may be possible that $\mathrm{Zn}$ provides protection to the spermatozoa during sperm cryopreservation. $\mathrm{Zn}$ inhibits the acrosome reaction before ejaculation of semen. Reactive oxygen species (ROS) production in semen during the time of stress has been associated with loss of sperm motility, decreased capacity of sperm-oocyte fusion and loss of fertility. $\mathrm{Zn}$ possesses anti-oxidative properties and it scavenges the reactive oxygen species produced by defective spermatozoa as well as leucocytes, hence increases fertility of bull. It prevents the spermatozoa from premature oxidation. $\mathrm{Zn}$ deficiency reduces the activity of enzyme dipeptidyl carboxypeptidase (DC), this enzyme is thought to be required for maturation and development of sperm cells (Reeves, 1990). Some of the most important enzymes of spermatozoa are $\mathrm{Zn}$ metalloenzymes like sorbitol dehydrogenase, lactate dehydrogenase, alkaline phosphatase, etc. These enzymes become dysfunctional when $\mathrm{Zn}$ is deficient (Bedwal and Bahuguna, 1994). In cattle, retention of zinc is significantly reduced by $24 \%$ with the exposure to high environmental temperature (32 to $39^{\circ} \mathrm{C}$ ) (Aboul-Naga, 1983) so requirement of Zinc in heat stress increases significantly. Requirement of Zinc for optimal reproduction is greater than the requirement for growth or maintenance. Stressed cattle tend to respond more favorably to supplemental organic $\mathrm{Zn}$ compared to inorganic zinc.

\section{Selenium}

It is involved in normal spermatogenesis and it is an essential component of a range of selenoproteins, including glutathione peroxidase, thioredoxin reductase and iodothyroninedeiodinase (Noblanc et al., 2011). It also plays a vital role in protecting both the intra- and extra-cellular lipid membranes against oxidative damage. It is involved in sperm formation by protecting spermatozoa from ROS. The dietary requirement of Se for most of the species is about $0.1 \mathrm{ppm}$. Revised requirement of selenium for better immune response in dairy animals is 0.3 ppm (FDA, 1987) and its dietary toxic level is 5ppm. More recently, the addition of organic Se at $0.3 \mathrm{ppm}$ as selenized yeast was approved in feeds for chickens, swine, turkeys, and cattle (FDA, 2003). Sodium selenite improves semen quality by increasing semen volume per ejaculate, spermatozoa motility and concentration and by decreasing percentage of dead spermatozoa, spermatozoa abnormalities, and acrosome damage (Marai et al., 2009). There are two major sources of Se for animals: Se naturally originating from plants, in the form of seleno-amino acids, including selenomethionine and selenocysteine and inorganic $\mathrm{Se}$ in the form of selenate or 
selenite. Selenized yeast has been reported as more bioavailable source of $\mathrm{Se}$ as compared to selenite (Juniper et al., 2006) thereby it significantly increases the scrotal length, its circumference and testosterone secretion.

\section{Copper}

$\mathrm{Cu}$ is necessary for many enzymes like the $\mathrm{Cu}-\mathrm{Zn}$ superoxide dismutase which is involved in sperm cell protection against free radicals. $\mathrm{Cu}$ prevents lipid peroxidation in spermatozoa membrane via the activity of superoxide dismutase. SOD catalyzes both extracellular and intracellular super oxide anion to $\mathrm{H}_{2} \mathrm{O}_{2}$ and molecular oxygen. It may also be involved in the stimulation of pituitary cells which control the release the LH hormone (Slivkova et al., 2009). It prevents premature hyper activation and capacitation induced by super oxide radicals before ejaculation of semen (Agarwal and Prabakaran, 2005). Deficiency of $\mathrm{Cu}$ leads to decreased libido, lower semen quality and induces severe damage to testicular tissue which may render the bull sterile. The normal body requirement of copper in dairy cattle is 10 ppm (NRC, 1996) but additional supplementation of copper is required for good quality semen production(Puls, 1994). However, copper requirements may vary by breed and some breeds maintain greater plasma concentrations of copper compared with other breeds (Mullis et al., 2003; Ward et al., 1995). Toxic $\mathrm{Cu}$ dietary concentration is $100 \mathrm{mg} / \mathrm{kg}$ of DM for all classes of cattle, including bulls. $\mathrm{Cu}$ deficiency in cattle is generally due to the presence of dietary antagonists, such as $\mathrm{S}$, Mo and Fe that reduce bioavailability of $\mathrm{Cu}$. The following mineral ratios may be helpful in maintaining $\mathrm{Cu}$ levels in blood: $\mathrm{Zn}: \mathrm{Cu}$ 4:1, $\mathrm{Cu}$ : $\mathrm{Mo} \mathrm{6:1} \mathrm{and} \mathrm{Fe}: \mathrm{Cu}$ 40:1 (Hutjens, 2000). Proper supplementation of copper along with healthy ratio with other minerals is required for production of good quality semen. During hot and humid seasons retention of copper decreases so additional amount of $\mathrm{Cu}$ is require for optimum production.

\section{Manganese}

Mn appears to have an important role in reproduction of breeding bull. There is large variation in Mn levels in common available feedstuffs. Fodders are generally adequate in Mn but concentrates may be deficient (Bhanderi et al., 2014). Generally, legume and grass hays have more $\mathrm{Mn}$ than corn or corn silage and interestingly $\mathrm{Mn}$ is reported to be more available in hay than silage (Puls, 1994). It is necessary for cholesterol synthesis (Kappel and Zidenberg, 1999), which ultimately is required for synthesis of the steroids, estrogen, progesterone and testosterone. Insufficient steroid production results in decreased circulating concentrations of these reproductive hormones resulting in abnormal sperm production in males. Recommended dietary concentration for bulls is $40 \mathrm{mg} / \mathrm{kg}$ of DMI (NRC, 1996) and toxic Mn dietary concentration is $1000 \mathrm{ppm}$ for all classes of cattle, including bulls. Antioxidant capacity of $\mathrm{Mn}^{2+}$ is related to effective quenching of peroxylradicals and superoxide anion (Coassin et al., 1992). It increases serum levels of puberty-related hormones. It protects the bull sperm against (lipid peroxidation) LPO/oxidative stress and facilitates the occurrence of capacitation and acrosome reaction after ejaculation of semen which is important in fertilization of sperm with oocyte.

\section{Iodine}

Iodine deficiency leads to delay in puberty, failure of fertilization, decrease in libido and deterioration of semen quality in males (Sathish Kumar, 2003). It is required in the synthesis of thyroxin hormone which regulate energy metabolism. Dietary requirement of 
iodine is $0.25 \mathrm{ppm}$ (NRC, 2001). Its maximum toxicity level is $50 \mathrm{ppm}$.

\section{Cobalt}

Cobalt is important component of vitamin $B_{12}$ enzyme. Cobalt is needed for synthesis of thymine which is required for DNA synthesis. So it plays role in cell division, and has a profound impact on growth and reproduction of animal. Dietary concentration for bulls is $0.1 \mathrm{mg} / \mathrm{kg}$ of DM (NRC, 2001) and its toxic dietary concentration is $10 \mathrm{mg} / \mathrm{kg}$ of $\mathrm{DM}$ for all classes of cattle, including bulls.

\section{Iron}

Iron is trace elements that present in cells and tissues in the male reproductive system. Within the male reproductive system, Sertoli and Leydig cells are important reservoirs of ferritin. The molecule acts as a readily available source of $\mathrm{Fe}$ for the developing spermatozoa, while providing an extra layer of protection to the testicular tissue (Wise et al., 2003). Iron is important components of catalase which is main antioxidant enzyme preventing fluctuations in ROS production and protecting the cellular structure and function against oxidative damage. CAT breaks $\mathrm{H}_{2} \mathrm{O}_{2}$ into $\mathrm{O}_{2}$ and water $\left(\mathrm{H}_{2} \mathrm{O}\right)$. Fe plays an important role in the synthesis of nucleic acids and proteins, electron transport, cellular respiration, proliferation and differentiation (Lieu et al., 2001), which are ultimately lead to spermatogenesis and spermatozoa metabolism (Wise et al., 2003). It is component of cytochrome enzyme which is important in electron transport chain and plays role in spermatozoa motility. Dietary requirement of iron is $50 \mathrm{ppm}$ in animal (NRC, 2001) and its dietary toxic concentration is $1000 \mathrm{ppm}$. However, their accumulation in large amounts may lead to metabolic disruptions which in turn could compromise male fertility.
Male reproductive efficiency can be improved through maintenance of proper trace mineral balances in animals. Supplementation of trace minerals during active reproductive phase of the animal will improve their reproductive performance, however care should be taken about the interaction with other minerals and over-supplementation. Organic Trace mineral supplementation produce better results due to its greater absorption and least interaction with other minerals. The feeding of antioxidants ( $\mathrm{Zn}, \mathrm{Se}, \mathrm{Cu}, \mathrm{Mn})$ during stress can improve health and fertility of the bull.

\section{References}

Aboul-Naga, A.I. 1983. The role of heat induced physiological changes of minerals metabolism in the heat stress syndrome in cattle. M. Sc. Thesis. Faculty of Agriculture, Mansoura University, Egypt.

Bedwal, R.S., and Bahuguna, A. 1994.Zinc, copper and selenium in reproduction.Experentia,.50: 626- 640 .

Bhanderi, B.M., Garg, M.R., and Sherasia, P.L. 2014.Mineral status of feeds, fodders and dairy animals in Jalgaon district of Maharashtra state. Sch. J. Agric. Vet. Sci. 1(4A): 222-226.

Coassin, M., Ursini, F., and Bindoli, A. (1992).Antioxidant effect of manganese. Archives of biochemistry and biophysics, 299(2): 330-333.

Dhami, A.J., Shelke, V.B., Patel, K.P. Paradva, J.P., and Kavani, F.S. 2001. Trace minerals profile of blood and seminal plasma of breeding bulls. Ind. J. Anim. Sci. 71(8): 761-763.

FDA, 1987. Food additives permitted in feed and drinking water of animals: selenium. Fed. Reg. 52, 10887.

FDA, 2003. Food additives permitted in feed and drinking water of animals: selenium yeast. Fed. Reg. 68, 52339-52340.

Hedaoo, M.K., Khlllare, K.P., Meshram, 
M.D., Sahatpure, S.K., and Patil, M.G., 2008. Study of some serum trace minerals in cyclic and non-cyclic surti buffaloes. Vet. World 1: 71-72.

Hutjens, M. F. (2000). Feeding management of the 40000 pound dairy herds.J. Dairy Sci. 83 (Suppl 1).

Juniper, D.T., Phipps, R.H., Jones, A.K., and Bertin, G. 2006. Selenium supplementation of lactating dairy cows: effect of selenium concentration on blood, milk, urine and feces. J. Dairy Sci. 89: 3544-3551.

Kappel, L.C., and Zidenberg, S. 1999. Manganese: Present Knowledge in nutrition, In: Brown ML (Ed.), International Life Sciences Institute Nutrition Foundation, Washington, pp. 308.

Kumar, N., Verma, R. P., Singh, L. P., Varshney, V. P., and Dass, R. S. (2006). Effect of different levels and sources of zinc supplementation on quantitative and qualitative semen attributes and serum testosterone level in crossbred cattle bulls. Reproduction Nutrition Development, 46(6): 663-675.

Kumar, S., 2003.Management of infertility due to mineral deficiency in dairy animals. In: Proceedings of ICAR summer school on "Advance diagnostic techniques and therapeutic approaches to metabolic and deficiency diseases in dairy animals". IVRI, Izatnagar, UP, pp. 128-137.

Lieu, P.T., Heiskala, M., Peterson, P.A., and Yang, Y. 2001.The roles of iron in health and disease. Mol. Asp. Med. 22: $1-87$.

Marai, I. F. M., El-Darawany, A. A., AbouFandoud, E. I., and Abdel-Hafez, M. A. M. (2009). Reproductive and physiological traits of Egyptian Suffolk rams as affected by selenium dietary supplementation during the sub-tropical environment of Egypt. Livest. Res.
Rural Dev. 21(21).

McDowell, L.R. 1992. Minerals in animal and human nutrition. Academic Press. New York.

Mullis, L. A., J. W. Spears, and R. L. McCraw. 2003. Effects of breed (Angus vs Simmental) and copper and zinc source on mineral status of steers fed high dietary iron. J. Anim. Sci. 81: 318 322.

National Research Council, (2001). Nutrient requirements of dairy cattle, seventh revised ed., National Academic Press, Washington, DC, USA.

National Research Council. 1996. Nutrient Requirements of Beef Cattle. 7th Ed. Washington, DC, National Academy of Sciences.

Noblanc, A., Kocer, A., Chabory, E., Vernet, P., Saez, F., Cadet, R., Con-rad, M., and Drevet, J.R. 2011. Glutathione peroxidases at work on epididymal spermatozoa: an example of the dual effect of reactive oxygen species on mammalian male fertilizing ability. J. Androl. 32, 665-671.

Omu.A.E..Dashti, H. and AI-Othman, S. 1998. Treatment of asthenozoospermia with $\quad \mathrm{ZnS04}$ : andrological immunological and obstetric outcome. Eur. J. Obst. Gynae. Reprod. BioI. 79: 179-184.

Puls, R. 1994.Mineral levels in animal health. Diagnostic Data.2nd Edition. Sherpa International, Clearbrook, BC, Canada.

Reeves, P.G. 1990. Zinc deficiency and dipeptidylcarboxypeptidase activity. Comparative effects on epididymis and testis of rats. Biol Trace Elem Res. 24(1): 1-11.

Roy, B. 2006. Influence of zinc supplementation on semen quality and sexual behaviour of Crossbred and Murrah buffalo bulls. Ph.D Thesis, National Dairy Research Institute, Karnal, Haryana. 
Slivkova, J., M. Popelkova, P. Massanyi, S. Toporcerova, R. Stawarz, G. Formicki, N. Lukac, A. Putala and M. Guzik. 2009. Concentration of trace elements in human semen and relation to spermatozoa quality. J. Envir. Sci. Health. 44: 370-375.

Ward, J. D., J. W., Spears, and G. P. Gengelbach. 1995. Differences in copper status and copper metabolism among Angus, Simmental and Charolais cattle. J. Anim. Sci. 73: 571-577.

Wise, T., Lunstra, D.D., Rohrer, G.A., and Ford, J.J. 2003.Relationships of testicular iron and ferritin concentrations with testicular weight and sperm production in boars. J. Anim. Sci. 81: 503-11.

\section{How to cite this article:}

Ravi Prakash Pal, Veena Mani, Shahid Hassan Mir, Ram Kumar Singh and Rachana Sharma. 2017. Importance of Trace Minerals in the Ration of Breeding Bull - A Review. Int.J.Curr.Microbiol.App.Sci. 6(11): 218-224. doi: https://doi.org/10.20546/ijcmas.2017.611.026 